\title{
Bioengineering Tools to Aid the Study of Oral Processing Deficiencies: A Pathway to Tailored Food Products
}

\author{
Laguna L, Tarrega A and Fiszman $\mathbf{S}^{*}$ \\ Institute of Agrochemistry and Food Technology, Spain
}

*Corresponding author: Fiszman S, Institute of Agro chemistry and Food Technology (IATA-CSIC), Agustín Escardino 7, 46890

Paterna (Valencia), Spain

\begin{tabular}{|c|c|}
\hline ARTICLE INFO & ABSTRACT \\
\hline Received: 㠈 October 29, 2019 & This review surveys the bioengineering tools available to measure and characterize \\
\hline Published: 豐 November 05, 2019 & the oral process during food intake. The human oral forces applied whilst eating \\
\hline
\end{tabular}

Bioengineering Tools to Aid the Study of Oral Processing Deficiencies: A Pathway to Tailored Food Products. Biomed J Sci \& Tech Res 22(3)-2019. BJSTR. MS.ID.003763.

\section{Introduction}

With advancing age, the loss of dental pieces, lower muscle force or a lack of coordination can hinder oral processing, making ordinary eating difficult. This situation usually gets worse over time, leading to unhealthy food choices and bad culinary practices. It was first reported some years ago that individuals with incomplete dentures had a low intake of raw vegetables [1]; the participants in that study reported avoiding vegetables because they were difficult to eat, resulting in a vitamin-deficient diet. Later [2] it was also pointed out that subjects with eating deficiencies need to overcook vegetables to make them softer, again leading to a low intake of thermolabile vitamins. As all of these changes occur naturally with age, the elderly are one of the most vulnerable populations. Previous research has shown that malnutrition in elderly people will encourage infections and that a loss of feeding ability is partly responsible for deterioration in their quality of life [3].

Some years ago, the concept of "eating capability" was proposed to measure the difficulty that individuals experience during the eating process [4]. In this latter study, a set of measurements was performed in subjects who were then asked about the difficulty they perceived when eating. This same method has been used with a range of products $[5,6]$. Although measuring eating capability helps in understanding eating difficulties, it does not provide information regarding the individuals' oral forces. To cast light on new solutions for individuals with difficulties in eating, the present paper reviews some bioengineering tools to measure and characterize the oral process during food intake, which might be useful for tailoring food on the basis of these parameters. Firstly, it explains the different actions that take place during oral processing according to the physical state of the food (solid or semisolid) and how this has traditionally been measured in food science. It then describes the different methods for measuring human oral forces whilst eating and identifies the research gaps.

Oral Actions When Eating Food: Biting, Chewing and Swallowing

The way that individuals manipulate food in their mouths depends very much on the physical (mechanical and structural) properties of the food product.

\section{The First Bite (Solid) And the First Spoonful (Semisolid)}

A one-bite sized piece of solid food (for example, a piece of steak cut on the plate) is normally placed directly inside the mouth. If the piece of food is bigger than a one-bite size (for example, a 
whole apple), a suitable portion size is bitten off with the teeth. The latter involves occlusion of the opposing edges of the upper and lower incisors [7]. During this first bite, sensory food information will be captured thanks to the displacement of the periodontal ligament and the sound emitted (if any) [8], affecting the speed of the bite, the force exerted [9] and the subsequent mastication process. Consequently, the whole masticatory strategy is decided at this first bite, unconsciously of course. For a semisolid food product such as a cream or puree, the tongue (rather than the teeth) plays an important role in perception of the food texture and the decision about how to handle it in the mouth. For any food system, mechanoreceptors and chemoreceptors located on the tongue surface are constantly capturing food texture and taste features [10], contributing to the adaptation of oral forces to the food bolus and to food enjoyment.

\section{Mastication of Solid Food}

After the first bite of a solid food, the chewing cycles follow a sequence. The actions include a pattern of rhythmic jaw-opening followed by jaw-closing movements [11]. During this period, the chewing action is constantly adapting to the physical properties of the food as it is being reduced to smaller and smaller particles and, with the help of the saliva, is formed into a cohesive, deformable mixture (the food bolus) [12]. Throughout this process, not only the jaw but also the tongue move against the palate to assist in the formation of the food bolus and provide extra sensory information regarding food texture and taste recognition [7], as described above.

\section{Oral Processing of Semi-Solid Food}

Semisolid foods like purees are habitually given to individuals with impaired oral processing. When these kinds of food are given to patients with swallowing disorders, their nutritional status and their hydration levels have been shown to improve [13]. Since mastication (teeth) is not involved, tongue movements together with some subtle mandibular movements are the key to enjoying these food products. Besides the movements of the oral organs themselves, other factors such as food temperature, saliva composition and enzyme levels are also continuously changing the mechanical properties of the food, so the oral movements and forces are constantly adapting to these changes.

\section{Swallowing the Food Bolus}

When the food particles are small enough and sufficiently lubricated (after chewing down in the case of a solid food and tongue manipulation in the case of a semisolid food) and a food bolus is created [14], the swallowing centre, located in the brainstem (medulla oblongata) $[15,16]$ is triggered. This action requires the proper coordination of twenty-five different muscles located along the mouth, pharynx, larynx and oesophagus [10].

\section{Measurable Food Properties in Relation to Oral Processing}

Food properties at the first bite. To ascertain the initial mechanical properties of a food (before eating), food scientists have used a variety of devices (such as the Texture Analyser by Stable Microsystems or the Universal testing machine manufactured by Instron) to register the resistance of a food material to compression or breaking as it deforms. The force is exerted by a probe attached to the mobile arm of the equipment. Probes of different geometries (normally well-defined regular solids) are available depending on the test to be performed. A curve of resistance to deformation or breakage as a function of time is normally recorded. From this curve, a series of mechanical parameters can be extracted to characterize the mechanical properties of the food piece. Stróżyk et al. [17] have recently fixed dentures (upper and lower incisors and canines) to the instrument to mimic the human bite. However, having only one force point for the whole denture might not be representative of humans, in whom forces are created along the entire mandible.

Hence, the normal practice in food texture analysis is to select the probe that best suits the type of action to be applied to the food piece (cutting, compression, puncture, bending, breaking), which normally depends on the aim of the study, and correlate the instrumental measurement with sensory perception. Food properties during mastication. Different mechanical masticators have been developed to mimic human mastication, such as the AM2 [18] to study bolus mechanical properties or bolus aroma release [19]. However, none of these allow for ongoing adaptation to oral bolus transformation [20] or provide information about human oral forces whilst eating. However, the study of boli formed in individuals' mouths and expectorated is a good tool for understanding how some food characteristics evolve whilst eating. The analysis of boli formed in vivo presents some difficulties, as a bolus is partly swallowed before the final swallow event [21]. However, this method has been used in a number of studies of solid food products like cheeses [22-24], bread and crackers [25,26] and meat $[27,28]$, as well as in semisolid food products $[29,30]$ and to compare different food matrices [12].

Food properties after mastication. It is generally agreed that food properties at the end of the mastication process (expectorated bolus) are the same as those of food at the beginning of the swallowing process, as no further chemical reaction or mechanical event will happen except for some bolus elongation. Also, once the food has travelled through the mouth to the oesophagus it is difficult to recover it in order to study the bolus properties at this point. Nonetheless, due to the swallowing difficulties that individuals experience, especially in old age, there is research to be done on further understanding the food swallowing process. For example, ultrasound measurement has been proposed as a noninvasive method for studying the food whilst swallowing [31,32]. Food researchers have also made efforts to mimic swallowing through experimental model systems, proposing different in vitro arrangements such as a two-roll coating configuration [33] or a roller attached to a pivoting arm to mimic the tongue when propelling a bolus [34]. However, the systems proposed up to now only work for flowing materials (such as thickened liquids or purees). 


\section{Human Eating-Related Characteristics That Can Be Measured with Bioengineering Tools}

\section{Incisal Bite Force While Eating}

The maximum force that can be applied by the incisors has frequently been quantified to gauge the efficacy of dentures or replacement teeth. One of the most frequently used devices is a system that has a thin sensor (Flexiforce, Tekscan) coupled to a calibrated transducer which transforms the resistance into a measurable force $[35,36]$. This tool has been used widely in assessing the eating capability of elderly individuals $[5,37]$ and has proved sufficiently discriminatory to assess the different forces exerted by individuals with natural teeth, dentures or fixed teeth The sensor has been validated for use in daily dental practice [38]. However, these measurements still fail to capture the force exerted when biting different food products. As this force depends on the properties (shape) of the sensor and the number of teeth involved, it would be useful in the future to have sensors located on each tooth whilst analysing the force required to take the first bite of different food products.

\section{Mastication Forces While Eating}

Tongue Force: As explained above, the tongue plays a key role in oral food processing and the initiation of swallowing. Tongue force is one of the most common measurements in a swallowing functionality assessment [39].The different devices designed to capture the force exerted by the tongue against the palate can be divided into those that consist of only one bulb (like the device by IOPI) [40] or of several bulbs [41] fixed to the palatal plates. However, although these bulbs provide plenty of information about individuals' oral motor functionality, they are not yet adequate for measuring tongue forces when eating food. Therefore, a palate sensor that can be easily stuck to the palate and does not interfere with oral food processing would be the most suitable for understanding tongue forces whilst eating [39].
Masticatory Muscle Strength: One of the most widely used devices to measure muscle activation whilst eating is the electromyography [42,43]. Electrodes are easily positioned on some facial muscles, such as the masseter and the suprahyoid muscle group, where the sensors do not interfere with the eating process. This method is quite widely used by food scientists with the aim of increasing their understanding of food texture appraisal during mastication. However, it only measures the muscle activity, not the force exerted when eating [44]. The use of intraoral bite force sensors has also been proposed to measure the mastication force whilst chewing. Carrot pieces of different sizes have been used to register pain and the biting force exerted [45]. This study was performed for medical purposes, but the tool has potential for adoption in food science to understand and measure oral food breakage forces.

Measurement of Swallowing Response: Great efforts have been made to understand the food swallowing process, both by clinicians and by food scientists. Due to the importance of the swallowing process and the health risk of impaired swallowing, clinical research has been conducted in depth. Food swallowing has been studied through video fluoroscopy, fibre optic endoscopy and ultrasound techniques. Electroglottography, normally used in speech therapy, has also been used to identify swallowing events during eating [46]. It is similar to electromyography and works by locating sensors on the skin over either side of the thyroid cartilage to detect muscular contractions; allowing the different stages of the swallowing process to be identified [47]. However, no non-invasive technique has yet been developed that enables the physical characteristics of the food product to be measured jointly with human-derived parameters. Table 1 summarizes the types of measurement that can be made in the food material and some of the available bioengineering tools for measuring human actions in different food states and sizes.

Table 1: Summary of possible measurements in the food material and in humans whilst eating foods in different states and sizes.

\begin{tabular}{|c|c|c|c|}
\hline Food State & Food Size & Instrumental Measurement of Food & Available Bioengineering Tool \\
\hline \multirow{6}{*}{ Solid } & \multirow{3}{*}{ Larger than one-bite size (e.g. apple) } & \multirow{5}{*}{$\begin{array}{l}\text { Cutting, compression, puncture, bending, } \\
\text { breaking resistance }\end{array}$} & - \\
\hline & & & \\
\hline & & & $\begin{array}{l}\text { Tongue force whilst eating food can be } \\
\text { recorded }\end{array}$ \\
\hline & \multirow{3}{*}{$\begin{array}{c}\text { One-bite size (e.g. any food previously cut } \\
\text { by a knife) }\end{array}$} & & $\begin{array}{c}\text { Masticatory forces whilst eating carrots } \\
\text { have already been measured }\end{array}$ \\
\hline & & & Electromyography \\
\hline & & & Electroglottongraphy \\
\hline \multirow{2}{*}{ Semi-solid } & \multirow{2}{*}{ - } & Flow properties & Electromyography \\
\hline & & Viscoelastic properties & Electroglottongraphy \\
\hline
\end{tabular}




\section{Conclusion}

This short review has shown the potential of some biomedical data acquisition methods for measuring human actions related to oral food processing and deficiencies in oral processing. It has discussed some existing bioengineering tools, normally used in clinical areas, which are suitable for studying human forces in different food breakdown and oral trajectories. These tools should be able to measure tongue force and masticatory force. Others, such as for the study of the swallowing process, are yet to be developed.

\section{Acknowledgement}

The authors are grateful to the Spanish Ministry of the Economy, Industry and Competitiveness (AGL-2016-75403-R), and to the regional government (Generalitat Valenciana Project Prometeo 2017/189), for financial support. Author Laura Laguna thanks the Spanish "Juan de la Cierva" program for her contract (IJCI2016-27427). Mary Georgina Hardinge provided English language editing assistance.

\section{References}

1. Ranta K (1988) Dental status and intake of food items among an adult Finnish population. Gerodontics 4(1): 32-35.

2. Walls AWG, Steele JG (2004) The relationship between oral health and nutrition in older people. Mech. Ageing Dev 125(12): 853-857.

3. Norman K, Pichard C, Lochs H, Pirlich M (2008) Prognostic impact of disease-related malnutrition. Clin. Nutr 27(1): 5-15.

4. Laguna L, Chen J (2016) The eating capability: Constituents and assessments. Food Qual. Prefer 48: 345-358.

5. Laguna L, Sarkar A, Artigas G, Chen J (2015) A quantitative assessment of the eating capability in the elderly individuals.Physiol. Behav 147 274-281.

6. Laguna L, Barrowclough RA, Chen J, Sarkar A (2016) New Approach to Food Difficulty Perception: Food Structure, Food Oral Processing and Individual's Physical Strength, J. Texture Stud 47 (5): 413-422.

7. Okada A, Honma M, Nomura S, Yamada Y (2007) Oral behavior from food intake until terminal swallow. Physiol. Behav 90: 172-179.

8. Chen J (2009) Food oral processing-A review, Food Hydrocoll 23(1): $1-25$.

9. Ang KY, Lucas PW, Tan HTW (2006) Incisal orientation and biting efficiency. J. Hum. Evol 50(6): 663-672.

10. Hiiemae KM, Palmer JB (1999) Food transport and bolus formation during complete feeding sequences on foods of different initial consistency. Dysphagia 14(1): 31-42.

11. Woda A, Foster K, Mishellany A, Peyron MA (2006) Adaptation of healthy mastication to factors pertaining to the individual or to the food. Physiol. Behav89(1): 28-35.

12. Jalabert Malbos ML, Mishellany Dutour A, Woda A, Peyron MA (2007) Particle size distribution in the food bolus after mastication of natural foods. Food Qual. Prefer 18(5): 803-812.

13. Rofes L, Arreola V, Almirall J, Cabré M, Campins L, et al. (2011) Diagnosis and management of oropharyngeal dysphagia and its nutritional and respiratory complications in the elderly. Gastroenterol. Res. Pract pp. 818979.

14. Hutchings JB, Lillford PJ (1988) The perception of food texture-the philosophy of the breakdown path. J Texture Stud 19(2): 103-115.

15. Clavé P, Shaker R (2015) Dysphagia: current reality and scope of the problem. Nat. Rev. Gastroenterol. Hepatol 12(5): 259-270.
16. Jean A (2001) Brain stem control of swallowing: neuronal network and cellular mechanisms. Physiol. Rev. 81(2): 929-969.

17. Stróżyk P, Bałchanowski J (2018) Modelling of the forces acting on the human stomatognathic system during dynamic symmetric incisal biting of foodstuffs. J Biomech 79: 58-66.

18. Woda A, Mishellany Dutour A, Batier L, François O, Meunier JP, et al. (2010) Development and validation of a mastication simulator. J Biomech 43 (9): 1667-1673.

19. Salles C, Tarrega A, Mielle P, Maratray J, Gorria P, et al. (2007) Development of a chewing simulator for food breakdown and the analysis of in vitro flavor compound release in a mouth environment. J Food Eng 82(2): 189-198.

20. Peyron MA, Santé Lhoutellier V, Dardevet D, Hennequin M, Rémond D, et al. (2019) Addressing various challenges related to food bolus and nutrition with the AM2 mastication simulator. Food Hydrocoll 97: 105229.

21. Hiiemae K, Heath MR, Heath G, Kazazoglu E, Murray J, et al. (1996) Natural bites, food consistency and feeding behaviour in man. Arch. Oral Biol41(2): 175-189.

22. Lorieau L, Septier C, Laguerre A, Le Roux L, Hazart E, et al. (2018) Bolus quality and food comfortability of model cheeses for the elderly as influenced by their texture. Food Res. Int 111: 31-38.

23. Saint Eve A, Panouillé M, Capitaine C, Déléris I, Souchon I (2015) Dynamic aspects of texture perception during cheese consumption and relationship with bolus properties. Food Hydrocoll 46: 144-152.

24. Mossaz S, Jay P, Magnin A, Panouillé M, Saint Eve A, et al. (2010) Measuring and predicting the spreading of dairy products in the mouth: sensory, instrumental and modelling approaches. Food Hydrocoll 24(8): 681-688.

25. Van Eck A, Hardeman N, Karatza N, Fogliano V, Scholten E, et al. (2019) Oral processing behavior and dynamic sensory perception of composite foods: Toppings assist saliva in bolus formation. Food Qual Prefer 71: 497-509.

26. Shiozawa K, Kohyama K (2011) Effects of Addition of Water on Masticatory Behavior and the Mechanical Properties of the Food Bolus. J. Oral Biosci 53(2): 148-157.

27. Yven C, Culioli J, Mioche L (2005) Meat bolus properties in relation with meat texture and chewing context, Meat Sci 70(2): 365-371.

28. Rizo A, Peña E, Alarcon Rojo AD, Fiszman S, Tárrega A (2019) Relating texture perception of cooked ham to the bolus evolution in the mouth. Food Res Int 118: 4-12.

29. Janssen AM, Terpstra MEJ, De Wijk RA, Prinz JF (2007) Relations between rheological properties, saliva-induced structure breakdown and sensory texture attributes of custards. J. Texture Stud 38(1): 42-69.

30. De Wijk RA, Janssen AM, Prinz JF (2011) Oral movements and the perception of semi-solid foods. Physiol. Behav 104 (3): 423-428.

31. Koshino H, Hirai T, Ishijima T, Ikeda Y (1997) Tongue motor skills and masticatory performance in adult dentates, elderly dentates, and complete denture wearers. J. Prosthet. Dent 77(2): 147-152.

32. Morinière S, Hammoudi K, Marmouset F, Bakhos D, Beutter P, et al. (2013) Ultrasound analysis of the upper esophageal sphincter during swallowing in the healthy subject. Eur. Ann. Otorhinolaryngol. Head Neck Dis 130(6): 321-325.

33. Mathieu V, De Loubens C, Thomas C, Panouillé M, Magnin A, et al. (2018) An experimental model to investigate the biomechanical determinants of pharyngeal mucosa coating during swallowing. J. Biomech 72: 144151

34. Hayoun P, Engmann J, Mowlavi S, Le Reverend B, Burbidge A, et al. (2015) A model experiment to understand the oral phase of swallowing of Newtonian liquids. J. Biomech 48(14): 3922-3928.

35. Fernandes Cp, Glantz POJ, Svensson SA, Bergmark A (2003) A novel sensor for bite force determinations. Dent. Mater 19(2): 118-126. 
36. Flanagan D, Ilies H, O brien B, Mc Manus A, Larrow B (2012) Jaw bite force measurement device. J. Oral Implantol 38(4): 361-364.

37. Laguna L, Sarkar A, Chen J (2017) Eating Capability Assessments in Elderly Populations.

38. Testa M, Di Marco A, Pertusio R, Van Roy P, Cattrysse E, et al. (2016) A validation study of a new instrument for low cost bite force measurement. J. Electromyogr. Kinesiol 30: 243-248.

39. Hori K, Ono T, Tamine K, Kondo J, Hamanaka S, et al. (2009) Newly developed sensor sheet for measuring tongue pressure during swallowing. J. Prosthodont. Res 53(1): 28-32.

40. Ono T, Hori K, Tamine K, Maeda Y (2009) Evaluation of tongue motor biomechanics during swallowing-from oral feeding models to quantitative sensing methods. Jpn Dent Sci Rev 45(2): 65-74.

41. Tsuga K, Hayashi R, Sato Y, Akagawa Y (2003) Handy measurement for tongue motion and coordination with laryngeal elevation at swallowing J. Oral Rehabil 30(10): 985-989.

\section{ISSN: 2574-1241}

DOI: 10.26717/BJSTR.2019.22.003763

Fiszman S. Biomed J Sci \& Tech Res

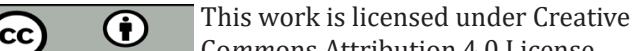

Submission Link: https://biomedres.us/submit-manuscript.php
42. Mioche L (2004) Mastication and food texture perception: Variation with age. J Texture Stud 35(2): 145-158.

43. Yemm R (1977) The representation of motor-unit action potentials on skin-surface electromyograms of the masseter and temporal muscles in man. Arch Oral Biol 22(3): 201-205.

44. Vinyard CJ, Fiszman S (2016) Using electromyography as a research tool in food science. Curr Opin Food Sci 9: 50-55.

45. Shimada A, Baad Hansen L, Svensson P (2015) Effect of experimental jaw muscle pain on dynamic bite force during mastication. Arch. Oral Biol 60(2): 256-266.

46. Carvalho da Silva AM, Van Damme I, Wolf B, Hort J (2011) Characterisation of chocolate eating behaviour, Physiol. Behav 104(5): 929-933.

47. Firmin H, Reilly S, Fourcin A (1997) Non-invasive monitoring of reflexive swallowing. Speech Hear. Lang 10: 171-184.

\begin{tabular}{|l} 
AIOMEDICAL \\
RESEARCHES
\end{tabular}$\quad$\begin{tabular}{l} 
Assets of Publishing with us \\
\hline
\end{tabular}

